\title{
Ballistic Response of Chromium/Chromium-Sulfide Cermets
}

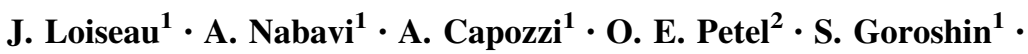 \\ F. Barthelat ${ }^{1} \cdot$ D. L. Frost ${ }^{1}$. A. J. Higgins ${ }^{1}$
}

Received: 9 June 2015/Accepted: 31 July 2015/Published online: 29 August 2015

(C) Society for Experimental Mechanics, Inc 2015

\begin{abstract}
In the present study, the ballistic response of chromium/chromium-sulfide cermet, a microstructural ceramic-metal composite, was investigated. The chromium/chromium-sulfide cermet was manufactured using self-propagating high-temperature synthesis, a process wherein the material is created under a self-sustaining combustion reaction between the chromium and sulfur. This type of synthesis allows the creation of near-net shape structures and offers the possibility of tuning material properties and material behavior by changing the reactant composition. High-speed ballistic impact $(\approx 1460 \mathrm{~m} / \mathrm{s})$ of samples with initial molar ratios of $\mathrm{Cr}: \mathrm{S}$ ranging from 1.15:1 to 4:1 exhibited a transition in response from purely brittle to quasi-ductile when the molar ratio was at and above 3:1. Microscopy of the impacted samples revealed that this ductility was sustained by significant deformation of metal chromium particles supported in the matrix of chromium-sulfide ceramic. Ballistic depth of penetration experiments at $\approx 1715 \mathrm{~m} / \mathrm{s}$ using thin cermet samples facing a polyethylene cylinder showed a weak dependence of residual penetration on molar ratio.
\end{abstract}

Keywords Cermet $\cdot$ SHS $\cdot$ Ballistic impact

A. Nabavi

atefeh.nabavi@mail.mcgill.ca

1 McGill University, Macdonald Engineering Building, 817 Sherbrooke Street West, Montreal, QC H3A 0C3, Canada

2 Department of Mechanical and Aerospace Engineering, Carleton University, 1125 Colonel By Drive, Ottawa, ON K1S 5B6, Canada

\section{Introduction}

The high compressive strength, hardness, and low density of ceramics have driven a rapid increase of their use in ballistic protection due to their ability to defeat projectiles via interface dwell and/or substantial erosion and destruction of the penetrating tip [1-3]. Ceramic armor development has typically focused on composite integration in order to compensate for undesirable brittle failure during ballistic impact. After a potential period of projectile dwell at the surface of the ceramic, penetration begins, resulting in limited plastic deformation and small-scale cracking of the ceramic immediately beneath the penetrator [4]. When the shock wave/compression waves from the projectile impact reach the back surface of an unconfined sample, they generate release waves that travel back towards the front surface of the sample. These intersect with release waves emanating from the front surface and edges, causing the ceramic to be put in tension and begin to laterally and radially crack ahead of the projectile, causing the formation of a characteristic fracture conoid [2, 5-7]. This precursor damage and comminution reduces the stress exerted on the projectile and thus substantially limits the ballistic resistance of the ceramic.

Composite schemes, wherein ceramic layers or inserts are pre-stressed and heavily confined by high-impedance materials, provide a means of leveraging the compressive strength and interface defeat capabilities of ceramics while mitigating the effects of precursor damage accumulation. Increasing the ballistic performance of ceramics via the simple addition of a metal backing plate was first described by Wilkins et al. [5, 8,9], and a large body of literature has followed, including the assessment of lateral confinement and ceramic pre-stressing as studied and summarized by Espinosa et al. [10]. The addition of a metal backing plate 
increases ballistic resistance by reflection of compression waves due to the higher material impedance, which delay the onset of comminution-producing tensile loading.

Conceptually, composite armor performance may be increased by further lamination of alternating layers of ceramic and metal, however experiments of this type have yielded conflicting results. Roeder and Sun showed that lamination reduced performance [11]. Conversely, Yadav et al. experimentally determined that introducing a polymer between ceramic layers modestly increased ballistic efficiency over monolithic ceramic plates of identical thickness, provided that the ceramic flexural strength was not excessively reduced [12]. Improved performance in this case was attributed to mitigation of damage propagation via crack deflection and stress wave dissipation. Alternatively, ceramic inserts (with insert size on the order of the penetrator diameter) can be incorporated into a metal matrix via hot isostatic pressing as reported by Yabei and Nesterenko [13]. Ballistic testing of this composite demonstrated significant penetrator deflection and yaw. Wadley et al. experimentally tested a variety of alumina insert geometries with slip-fit and press-fit interfaces between the insert and metal confinement and confirmed the importance of constraining ceramic deformation and damage in optimizing ballistic resistance [14].

Additionally, the ballistic resistance of ceramic armors may be improved via microstructural tailoring, including the formulation of microstructural composites comprised of intermixed ceramic and metal phases (cermets). Chan reviewed the manufacture of layered ceramics involving microstructural enhancement for structural applications [15]. Similarly, several microstructural composites have been evaluated for armor applications. Of particular interest is the use of microstructural tailoring to produce functionally graded armor materials (FGM). Cermets can be used to bond a monolithic ceramic to its monolithic metal confinement with a smoother transition in material properties and impedance, thereby potentially augmenting composite array performance.

A microstructural composite can be formulated by incorporating small particles or whiskers into a bulk metal, resulting in a particle-reinforced metal-matrix composite (MMC) that has material properties intermediate between the monolithic metal and the ceramic [16]. A general review of MMCs and their properties is presented by Ibrahim [17] and the effect of ceramic particle volume fraction and morphology is presented by $\mathrm{Li}$ and Ramesh [18]. For MMCs with large volume fractions of ceramic inclusions, features typical of a ceramic-like ballistic response can be observed and ballistic resistance can be increased over the base metal with a significant reduction in depth of penetration [19]. An alternative microscale composite morphology is the use of interpenetrating metal and ceramic phases rather than relying on disperse ceramic phase/inclusions. A review of the fabrication and mechanical properties of these interpenetrating composites (IPC) is presented by Clarke [20].

Functional grading between the ceramic and confinement metal can be accomplished via several manufacturing techniques. Gooch et al. described the use of sequential, liquid-phase hot pressing of different ratios of titanium and boron powders to produce a material gradient between a titanium-boride $(\mathrm{TiB})$ front plate and a titanium back plate [21]. Reaction during hot pressing formed $\mathrm{TiB}$ whiskers in a metal matrix between the monolithic TiB face and titanium metal backing. The resulting material showed unique damage response under ballistic impact. Alternatively, the gradient can be constructed by bonding a ceramic front face to a metal backing with an IPC. Chang et al. fabricated IPCs by infiltrating molten aluminummagnesium alloy into an alumina foam [22, 23]. While the resulting IPC demonstrated no advantages in ballistic resistance on its own, it was successfully used as the intermediate component in a composite array that had a monolithic alumina front face and a monolithic aluminum backing. Ballistic resistance of the resulting composite was attributed to layer bonding and impedance matching. This demonstrates how microscale composite manufacture enables performance enhancing functional grading of properties in a traditional metal-backed ceramic armor system. Of particular interest to the current study was the observation of ductile-like behavior of the IPC despite the continuous network of alumina present [22,23]. Similarly, Templeton et al. computationally studied the ballistic efficiency of a functionally graded metal-ceramic laminated system compared to an equivalent system with abrupt metal-ceramic interfaces and found a $15 \%$ improvement in ballistic performance [24].

Aluminum/Boron-Carbide cermets have also been studied and evaluated for structural and ballistic applications. Halverson et al. presented an initial study of manufacturing $\mathrm{BC}-\mathrm{Al}$ to overcome some of the toughness and porosity limitations of monolithic boron carbide [25]. Stachiw et al. and Pyzik et al. reported that the greatest strength was obtained when boron carbide and aluminum were present as continuous and interpenetrating phases, whereas the maximum fracture toughness was observed when boron carbide was present only in isolated grains surrounded by densified aluminum [26, 27]. These studies illustrate the potential of optimizing cermet material properties via tailoring microstructure morphology as well as pre- and post-processing.

Microscale cermets can also be manufactured via selfpropagating high-temperature synthesis (SHS). SHS fabrication leverages the exothermic reactivity of metals, metal oxides, and metalloids to produce refractory materials with 
intermediate properties. SHS manufacturing offers several advantages over conventional refractory cermet fabrication techniques, such as the elimination of high temperature furnaces and shortened fabrication times. For some SHS compositions, near-net shapes can be produced during combustion and then subsequently hardened via baking, thereby providing a manufacturing path for complex geometries without the need for hot-pressing. SHS also allows the manufacture of metalized ceramic composites (cermets) with tunable material properties by varying the initial mass fractions of the reactants. Reviews of the SHS technique are presented by Merzhanov [28, 29], and Subrahmanyam and Vijayakumar [30].

The particular SHS mixture studied in this paper is the chromium/chromium-sulfide $(\mathrm{Cr} / \mathrm{CrS})$ system. This is only one representative example of a cermet that can be prepared using self-propagating synthesis in metal-sulfur systems. Goroshin et al. showed that most metals generate sufficient exothermicity to enable a self-propagating reaction [31]. The reaction properties (i.e., ignition temperature, etc.) of seven different metals reacting with sulfur have been further thoroughly characterized $(\mathrm{Cr}, \mathrm{Mg}, \mathrm{Si}, \mathrm{Ti}$, $\mathrm{Mn}, \mathrm{Zn}$, and Mo) [31]. The use of low melting temperature sulfur (m.p. $115^{\circ} \mathrm{C}$, much less than the typical $300-600{ }^{\circ} \mathrm{C}$ ignition temperature), allows the green composition to be safely melted without reaction prior to the initiation of the SHS flame. This enables the mixture to approach theoretical maximum density (TMD) without mechanical pressing. The subsequent SHS process can be effected either in a molten state or in the re-solidified green composition [32]. The ability of the reaction to proceed with metal to sulfur ratios much greater than stoichiometry (e.g., metal to sulfur equivalence ratios of 4 or greater) permits the ratio of metal to ceramic in the product to be easily varied. Cermet composition can thus be varied from essentially entirely metal-sulfide ceramic to a microstructural composite composed mostly of a metallic phase with an interstitial sulfide network. In addition, many metal-sulfur SHS reactions result in predominately liquid-phase sulfide and metal products at the adiabatic flame temperature [33], ensuring the product retains the desired shape of the mold and gases that might evolve during the reaction process can escape, in principle resulting in product close to TMD. The solidification of the SHS product can be controlled using established directional solidification procedures, enabling a further degree of control of the product [34].

Chromium-sulfide $(\mathrm{CrS})$ has previously been evaluated for use as a solid lubricant by Tomoshige et al. [35]. The quasi-static material properties have been investigated by Nabavi et al. [36] and the planar shock response has been investigated by Petel et al. [37], however the high-strain rate response of the material has not been extensively studied to date. On the basis of the low-strain rate properties reported by Nabavi and summarized in Table 1 , and the low dynamic shear strength of $\approx 1 \mathrm{GPa}$ reported by Petel [37], $\mathrm{Cr} / \mathrm{CrS}$ cermets are not an ideal candidate material for high-performance armor inserts as they possess higher density, much lower hardness, and broadly similar toughness compared to traditional ceramic armor materials. However, the $\mathrm{Cr} / \mathrm{CrS}$ cermet is an ideal model material to examine the influence of microstructure and functional grading on ballistic response due to the simplicity of synthesizing the material using modest laboratory facilities as well as its amenability to substantial microstructural modification via straightforward variation in reactant mass fractions. Micrographs of non-impacted samples of 1.15:1, and 4:1 Cr:S cermets are depicted in Fig. 1, illustrating the transition from a nearly homogeneous ceramic to a twophase composite material composed primarily of metallic chromium inclusions surrounded by a chromium sulfide network. The lightly colored phase is metallic chromium, while the darker, mottled phase is chromium sulfide.

In the current study we considered the variation in ballistic response of $\mathrm{Cr} / \mathrm{CrS}$ cermets as a function of metallic chromium content under two ballistic test conditions. In the first experimental set, thin cermet samples (3.5 mm thickness) were fully confined in a metal anvil and impacted with small steel spheres at $\approx 1460 \mathrm{~m} / \mathrm{s}$. Macroscale observation of crater formation, fragmentation and cracking of recovered samples as well as electron microscopy of the impact zone revealed material dependent variations in damage response. In the second experimental set, $\mathrm{Cr} / \mathrm{CrS}$ cermet disks of constant areal density but differing composition were used to face a long cylinder of high-density polyethylene. The cermet disks were then impacted at $\approx 1715 \mathrm{~m} / \mathrm{s}$ by a $2.85 \mathrm{~g}$ fragment simulating projectile (FSP), and the residual depth of penetration into the polyethylene was measured.

\section{Material Synthesis and Sample Preparation}

A detailed description of chromium/chromium-sulfide cermet manufacturing is reported by Nabavi et al. [34]. Samples for the ballistic tests were prepared using this

Table 1 Summary of material properties for chromium/chromiumsulfide cermet at varying molar ratios as reported by Nabavi [36]

\begin{tabular}{lllll}
\hline & \multicolumn{4}{l}{ Molar ratio } \\
\cline { 2 - 5 } Property & $1.15: 1$ & $2: 1$ & $3: 1$ & $4: 1$ \\
\hline Density $\left(\mathrm{g} / \mathrm{cm}^{3}\right)$ & 4.0 & 4.7 & 4.9 & 5.4 \\
Vickers hardness $(\mathrm{MPa})$ & 221 & 239 & 258 & 305 \\
Flexural strength $(\mathrm{MPa})$ & 445 & 558 & 630 & 713 \\
Young's modulus $(\mathrm{GPa})$ & 108 & 138 & 153 & 186 \\
Fracture toughness $\left(\mathrm{MPa} \cdot \mathrm{m}^{1 / 2}\right)$ & 2.4 & 3.2 & 3.5 & 4.1 \\
\hline
\end{tabular}



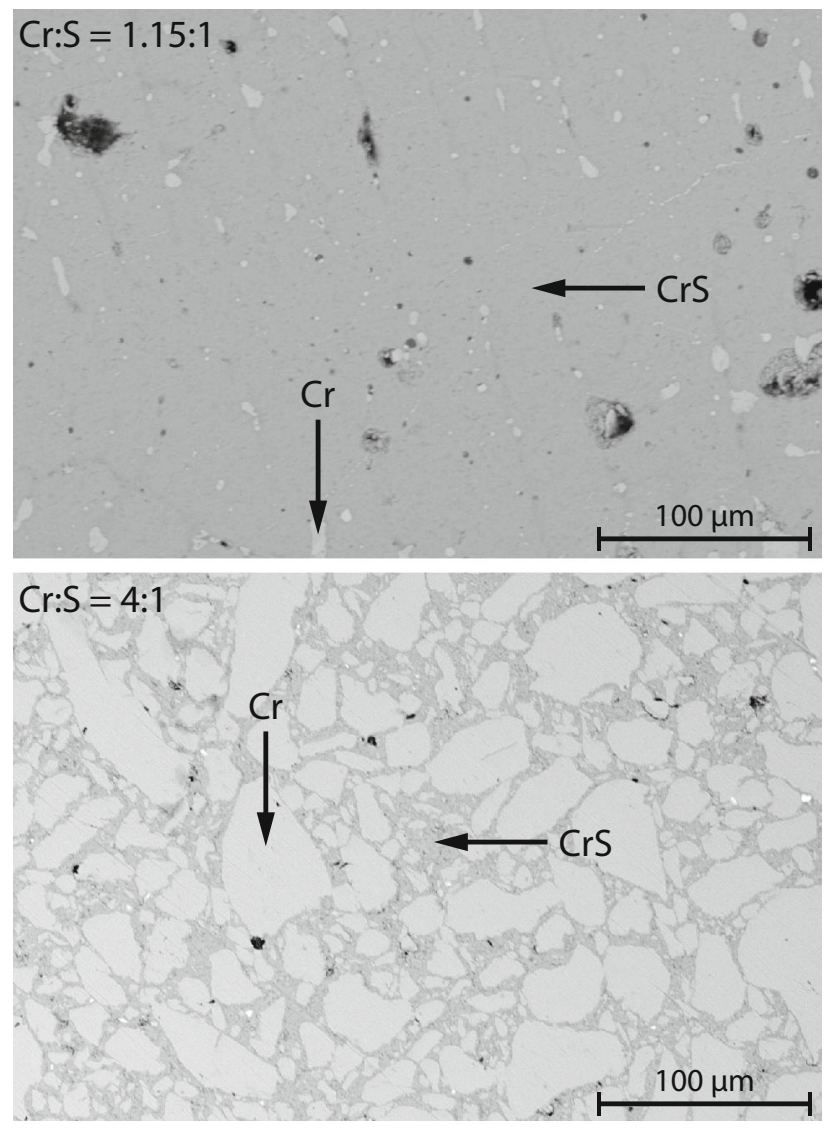

Fig. 1 Micrographs of non-impacted a 1.15:1 and b 4:1 cermets. The light gray phase is metallic chromium, while the darker matrix is chromium sulfide

methodology, which is summarized here. The cermet was synthesized by combusting a "green" mixture of chromium particles cast in a matrix of sulfur. Four cermets were produced using Cr:S molar ratios of 1.15, 2:1, 3:1, and 4:1. The resulting mechanical properties of the different formulations are summarized in Table 1. The sulfur was obtained from American Chemicals Ltd. (QC, CAN) with a purity of $99.5 \%$ (catalog \#S4981). The chromium powder was obtained from Atlantic Equipment Engineers (NJ, USA) in three particle size ranges: fine $(1-5 \mu \mathrm{m})$ with a purity of $99.8 \%$, medium $(45 \mu \mathrm{m})$ with a purity of $99.95 \%$, and coarse $(152 \mu \mathrm{m})$ with a purity of $99.8 \%$. The green material was prepared by combining the powders dry and then heating the mixture to the melting point of sulfur. The molten mixture was then vacuum degassed and cast into a heated, thin-walled, steel tube mold. Nichrome wires were embedded at the top of the mixture to initiate the combustion reaction. The green mixture was allowed to solidify prior to being reacted.

To prepare green mixtures with acceptable rheology for casting at high chromium concentrations, and to prevent chromium settling at low concentrations, a different combination of chromium particle sizes was used for each mixture. These formulations were determined empirically. Large chromium particle sizes resulted in fluid molten mixtures that were easy to vacuum degas and cast. However, mixtures with large particles tended to experience substantial settling during casting, leading to substantial material non-uniformity. If very large chromium particles were used, small quantities of sulfur may have evaporated prior to reacting completely with the chromium. Conversely, fine particles produced thick, paste-like mixtures that were difficult to cast and degas, but which reacted more completely and produced, more uniform product concentrations, and more homogeneously mixed phases. Consequently a balance had to be met to produce a uniform, low porosity, and completely reacted sample for each green mixture composition. Table 2 summarizes the molar ratios of each constituent for the four cermet formulations considered. Note that the chromium powder sizes in the green mixture did not strongly correlate with the sizes of metallic chromium inclusions left in the reacted sample due to the melt-diffusion process responsible for the formation of the interstitial $\mathrm{CrS}$ phase. This results in dispersed excess chromium particles suspended in a network of chromium sulfide. The post-reaction chromium particle size distribution was quite broad for all formulations but did not vary substantially as a function of green mixture particle size providing that the reaction went to completion and sulfur vaporization was suppressed; conditions that were met in the manufacture of the samples used in the present study [34].

In order to ensure low porosity and eliminate large central void formation, the combustion reaction must be performed under a high-pressure, inert gas atmosphere and directional solidification techniques must be used. The cast green mixtures were therefore placed in a cylindrical vessel and pressurized to $140 \mathrm{~atm}$ (14 MPa) with argon prior to being ignited with the nichrome heating wires. Directional solidification was accomplished by placing an annulus of green mixture around the outer wall of the steel mold that was ignited simultaneously with the main green mixture. This outer jacket of reacted SHS insulated the cooling inner mixture such that heat transfer predominantly occurred through the steel base of the mold. This caused the solidification wave to travel from the base of the mixture up the length of the sample, thereby ensuring that thermal shrinking occurred predominantly in the longitudinal direction. This prevented the formation of a large central void. When combined, these two techniques reduced the observed porosity to around $7 \%$ per volume in samples manufactured for ballistic tests. Figure 2 illustrates the effect of pressurization and directional solidification on cermet porosity, cracking, and void formation. For the low metal content cermet, a molar ratio of $1.15: 1$ was used instead of an exactly 1:1 green mixture because use of the 
Table 2 Green mixture powder composition for the four permutations studied

\begin{tabular}{lllll}
\hline Cr:S & $\begin{array}{l}\text { Sulfur } \\
(\% \text { mols })\end{array}$ & $\begin{array}{l}\text { Fine Cr } \\
(\% \text { mols })\end{array}$ & $\begin{array}{l}\text { Medium Cr } \\
(\% \text { mols })\end{array}$ & $\begin{array}{l}\text { Coarse Cr } \\
(\% \text { mols })\end{array}$ \\
\hline $1.15: 1$ & 46 & 42 & 12 & 0 \\
$2: 1$ & 33 & 12 & 13 & 42 \\
$3: 1$ & 25 & 6 & 69 & 0 \\
$4: 1$ & 20 & 5 & 60 & 15 \\
\hline
\end{tabular}

(a)
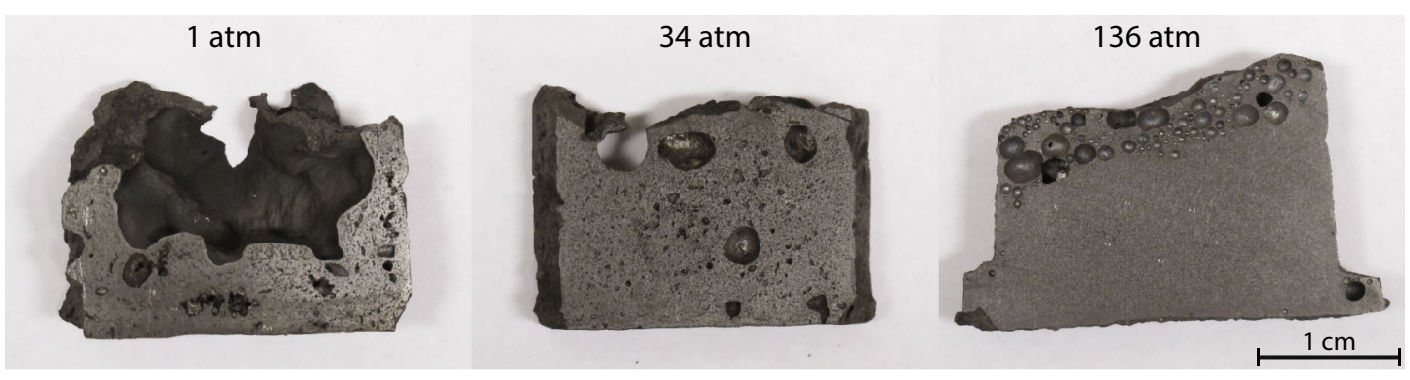

(b)
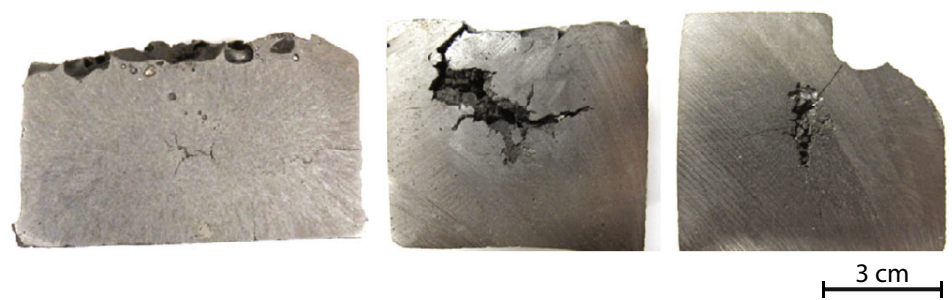

Fig. 2 a Effect of ambient pressurization on the formation of voids in the cermet. b Examples of cracking and large central void formation in the absence of directional solidification

latter resulted in traces of excess sulfur after reaction. These traces subsequently vaporized and generated substantial porosity during solidification. The addition of a slight excess of chromium eliminated this problem, but resulted in small quantities of dispersed metallic chromium being present in the sample as shown in Fig. 1a.

After recovery of the reacted cylindrical samples, disks were cut using an abrasive wet saw. Approximately the top quarter to top third of the sample was discarded due to the formation of large voids that resulted from vaporized sulfur rising and coalescing at the top of the solidifying reacted mixture. The remaining low-porosity sample was sectioned into disks and then ground to the desired thickness. An example of a cylindrical sample prior to sectioning is shown to the right of Fig. 2a. The outer diameters of the disks were also machined to ensure a consistent degree of radial confinement when the samples were integrated into the test fixture.

\section{Description of the Material Damage Ballistic Tests}

A velocity-calibrated single-stage light-gas gun was used to propel spherical impactors into the cermet samples. The gas gun consisted of a 1.48-cm-internal diameter stainless steel driver tube (34 cm long), a double-diaphragm firing mechanism, a 2.1-m-long hardened steel launch tube with an internal diameter of $7.1 \mathrm{~mm}$, and a sabot stripping section. The double diaphragm section enabled predictable gun operation and relatively fine control of muzzle velocity ( $\approx \pm 25 \mathrm{~m} / \mathrm{s}$ for velocities over $1000 \mathrm{~m} / \mathrm{s}$ ) by more precisely controlling the degree of pressurization before bursting of the final diaphragm. During gun pressurization with helium, the intermediate section between the two diaphragms was initially pressurized to approximately half of the final driver pressure prior to pressurization of the driver itself. The intermediate section was then quickly vented to fire the gun. By carefully selecting diaphragm material and thickness, the diaphragms can be made to easily resist the pressure gradients imposed between the driver, intermediate section and the barrel. Upon venting of the intermediate section, the diaphragms sequentially experience the full pressure gradient imposed by the driver and promptly rupture.

The impactors were $3.2 \mathrm{~mm}$ diameter, hardened steel spheres obtained from McMaster-Carr (part \#9670K11). Reference hardness and yield strength were Rockwell C60C65 and 2.2 GPa, respectively. The projectile was subcaliber and was launched with a polycarbonate sabot carrying an on-board rare-earth magnet (NdFeB magnet, MAGCRAFT part \#NSN0591). Coil gauges made of tightly-wound transformer wire were used to measure 
projectile velocity via induced voltage from the passage of the rare-earth magnet through the coil. The sabot was separated from the projectile with a combined gasdynamic and mechanical stripper. Another double diaphragm section downstream of the coil gauges was pressurized to $20 \mathrm{~atm}$ with nitrogen. As the combined sphere/sabot entered the pressurized gasdynamic stripper, the pressure drag differential from the precursor shock caused the sabot to separate and lag behind the small sphere. A sub-caliber "cookie-cutter" and deflection plate at the end of the section allowed the sphere to exit the stripper cleanly but arrested or deflected the sabot mechanically. A Photron SA5 high speed camera was used to verify impactor velocity and ensure that the sabot was separated cleanly and that no fragments generated by the mechanical stripper reached the cermet target. A schematic of the launcher is depicted in Fig. 3.

The target fixture for holding and confining the cermet sample was adapted from the experimental setup described by Normandia [38]. A two part steel anvil with a cylindrical pocket and a bolt-on flange was used to retain a sandwiched cermet sample. The sample sandwich was composed of a steel face plate with a $12.7 \mathrm{~mm}$ diameter hole to admit the impactor but prevent extreme sample breakup during impact fragmentation, a $3.5 \mathrm{~mm}$ thick cermet sample, and a $12.7 \mathrm{~mm}$ thick disk of 6061-T6 to act as a backing. The cermet sample was annularly confined by a steel ring of slightly greater thickness. The sample had a tight slip fit with the ring and was not compressed by the flange. Consequently the samples were consistently not pre-stressed during testing. A schematic and photograph of the anvil are depicted in Fig. 4.

\section{Discussion of Material Damage Results}

Sets of samples for each cermet formulation were impacted at $1464 \pm 25 \mathrm{~m} / \mathrm{s}$. These samples were recovered in their retaining rings and processed photographically. Representative post-impact samples for the 1.15:1, 3:1, and 4:1 formulations are depicted in Fig. 5. The variation in

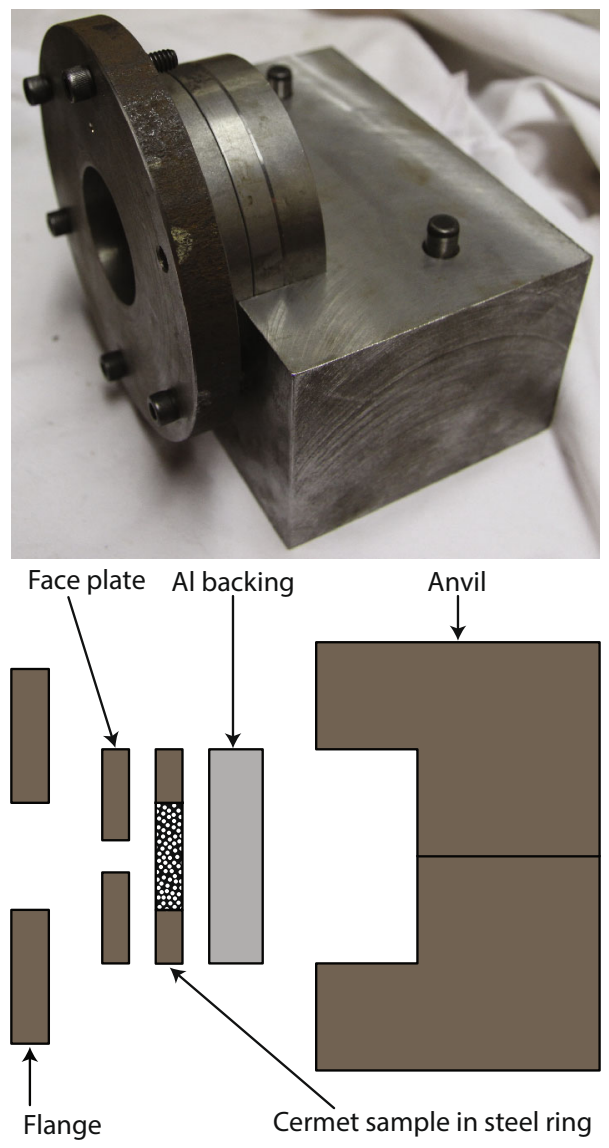

Fig. 4 Anvil and confinement sandwich used to support the cermet sample

material response as a function of cermet metal content can be qualitatively analyzed in the context of phenomenological responses to ballistic impact typically observed in conventional engineering materials. Ballistic impact of brittle ceramics is typified by extensive pulverization and cracking from tensile loads arising from the impact. In contrast, ductile penetration is associated with the penetrator plastically displacing target material out of its path, with perforation terminating either with petalling or shear plugging.

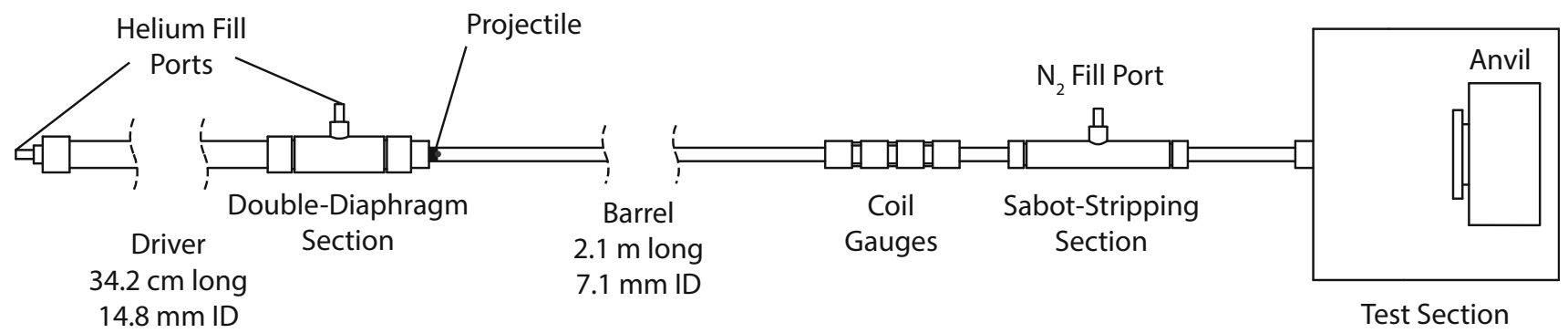

Fig. 3 Schematic of the single stage light-gas gun 

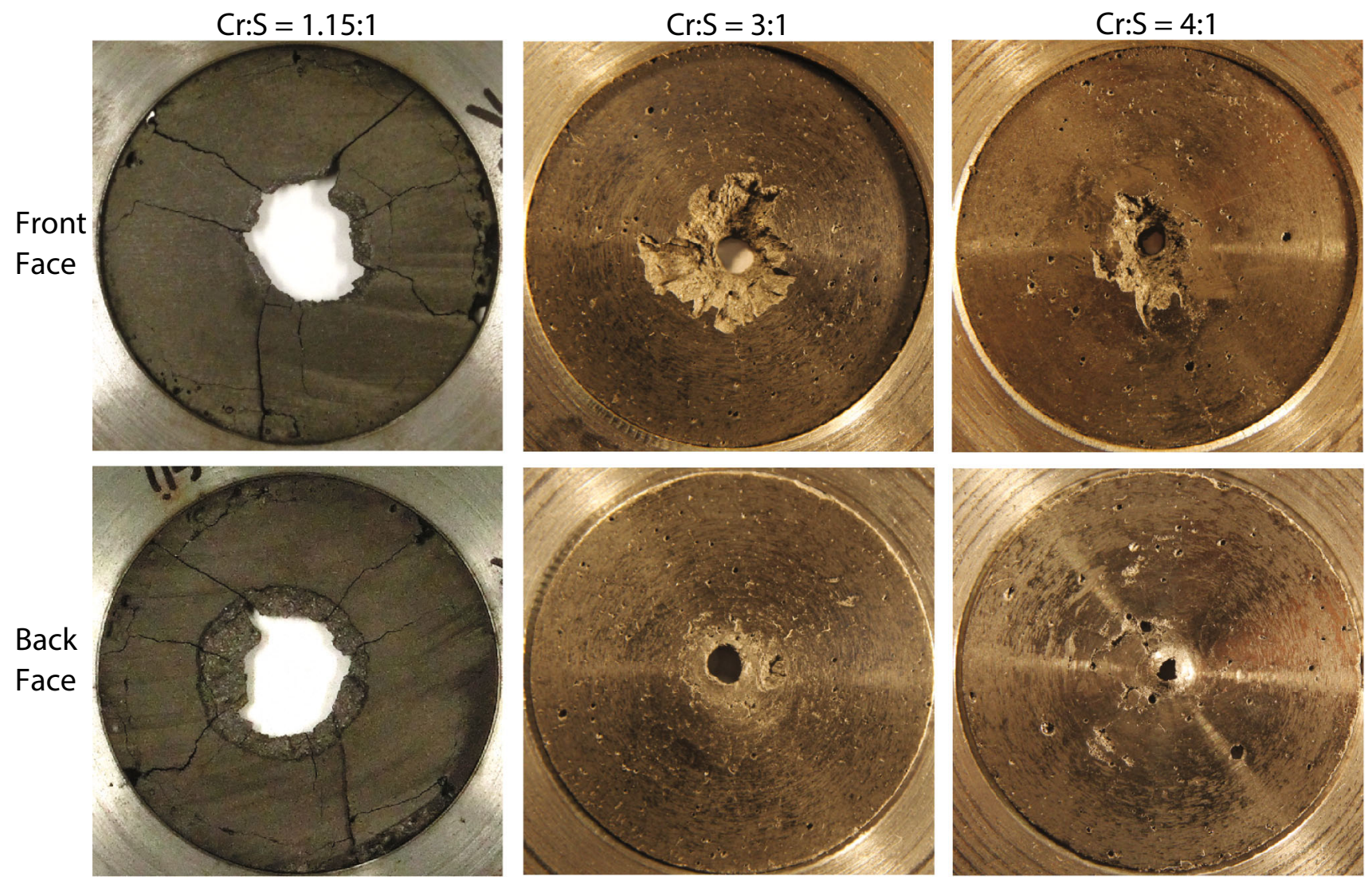

Fig. 5 Photographs illustrating material damage after impact by the $3.2-\mathrm{mm}$-diameter steel sphere at a mean velocity of $1464 \mathrm{~m} / \mathrm{s}$. The upper row shows the impacted faces, while the lower row shows the back faces. The 1.15:1 sample had a significant volume of pulverized material and radial through-cracking, whereas the 3:1 and 4:1 samples had more localized damage and quasi-ductile perforations. The 4:1 sample was recovered with a ductile dome beneath the penetrator and was not completely perforated.
Impacted 1.15:1 samples universally exhibited a large circular region of substantial pulverization as well as extensive radial cracking through to the sample edge. Additional material was fragmented on the sample back faces, as can be seen in Fig. 5. Qualitatively, damage observed in the 2:1 samples was indistinguishable from what was observed in the 1.15:1 samples. Microscopy of the fracture interfaces revealed no observable/measurable plasticity in the microstructure, indicating an entirely brittle response similar to what was observed by Nabavi et al. [36] in quasi-static fracture tests. Material damage in the 1.15:1 and 2:1 samples was thus broadly consistent with the brittle response of conventional ceramics to ballistic impact.

For the samples with large molar ratios of metallic chromium (3:1 and greater) a different damage pattern was observed. Extensive radial cracking through to the sample edges was entirely suppressed. Recovered samples had a region of conical pulverization on the front surface that tapered down to a final perforation channel with a diameter on the order of the size of the penetrator. The sample back surfaces beyond the perforation channel remained integral but heavily microcracked. This "reverse-cone" morphology is atypical of conventional ceramics. Gooch et al. [21] observed a narrowing of the penetration channel in FGM multiphase regions with higher metal content, which is qualitatively similar to the damage reduction in high metal content $\mathrm{Cr} / \mathrm{CrS}$ cermets observed here. This suggests that high metal content results in a penetration channel with morphology unique to cermets.

In the 3:1 samples, complete perforation was typical, with the region of conical pulverization tapering down to a final perforation channel width with approximately twice the diameter of the impactor. Front face damage in the 4:1 samples was substantially reduced as compared to the $3: 1$ samples, and incomplete perforation of the samples was typically observed. Again, the region of pulverization tapered down through the thickness of the sample. However, in the 4:1 samples, the penetration cavity typically terminated in a hemispherical cavity with a diameter approximately equal to the projectile diameter. This hemisphere was locally driven beyond the back surface of the sample and into the aluminum backing plate. Microscopy of a post-impact 4:1 sample sectioned in half and 
imaged along the cut is shown in Fig. 6. Visible is the characteristic tapering cone resulting from the ejection of pulverized material from the front face of the sample. The hemispherical terminal cavity is also visible in Fig. 6a.

Increased metal content in the cermet resulted in a transition from highly brittle response, with significant material damage over a large sample volume, to a response consistent with partially ductile deformation directly beneath the impactor. This ductile-like response was further investigated via electron microscopy of the impact crater in a 4:1 sample in order to determine the behavior of the two phases at the microstructural level. Electron micrographs of various regions of the crater are depicted in Fig. 6. As can be seen from micrographs in Fig. $6 \mathrm{~b}$ and d, the typically randomly sized and oriented $L: D=1: 1-4: 1$ chromium grains (as shown in Fig. 1) have been dramatically deformed into wavy, lamellar features conforming to the curvature of the impact crater. Measurement of these deformed grains indicated $L: D$ aspect ratios of 10:1 to 20:1. A conservative estimate based on this change in aspect ratio suggests local engineering strains of at least 0.6. Surprisingly, layers of intact chromium-sulfide appear to persist between the heavily deformed grains. In Fig. $6 \mathrm{c}$ and d cracking can be observed that is preferentially directed around metal chromium grains and through the interstitial chromium sulfide network. A large band of intact sulfide can also be observed in a semi-circular configuration towards the bottom corner of Fig. 6b. Since this region occurs within the quasi-ductile semi-circular terminal penetration cavity, it must have experienced strain beyond what the base material could sustain without fracture.

On the basis of these observations, a mechanism for the quasi-ductile response is proposed, where a competition between cracking and tensile failure of the interstitial sulfide layer and the plasticity and crack deflecting properties of the metal grains determines the morphology of the

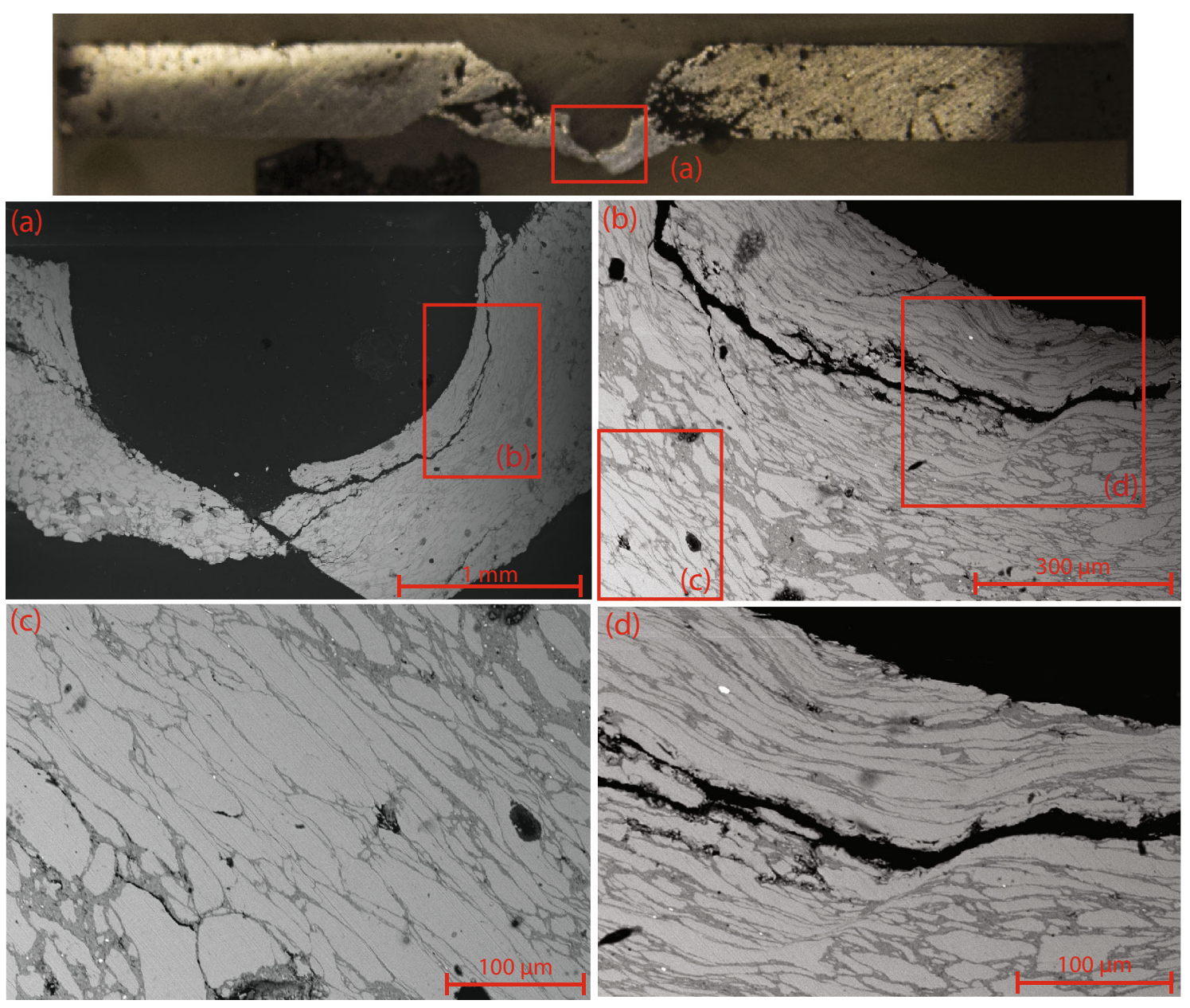

Fig. 6 Micrographs of a 4:1 sample impacted at $1473 \mathrm{~m} / \mathrm{s}$. a Shows the entire cavity left by the penetrating sphere. b Shows a magnified image illustrating significantly deformed chromium grains with a wavy structure. c Depicts a further magnified image showing extreme grain compaction and micro-cracking at the chromium metalchromium sulfide interface. d Shows a further magnified image of the wavy structure formed around the large crack 
impact crater. Directly beneath the projectile, large compressive stresses are maintained during penetration. Under these conditions the metal grains substantially deform but also act to restrain cracking and confine pulverized sulfide, which is subsequently dynamically re-sintered in the terminal phases of penetration. The presence of the aluminum backing plate and anvil support is likely essential to sustaining the high pressures required to achieve these large grain deformations and dynamically resinter the sulfide at the base of the penetration cavity in the high metal content samples, either by preventing the early onset of release waves from the back surface, or reflecting strong compressions towards the projectile depending on the interface impedance mismatch. Conversely, in the regions beside the penetrator, tensile loading from relief waves from the top surface and sample edges causes the nucleation of cracks within the sulfide at the metal grain boundaries, resulting in bulk pulverization and ejection of material. This results in the anomalous "reverse-cone" observed in the high-metalcontent cermets (molar ratio of 3:1 and greater).

The abrupt transition in behavior from an entirely brittle response to one typified by relatively localized damage and limited ductility between the 2:1 and 3:1 samples, despite only modest changes in bulk material properties, provides further evidence that a microstructural effect is responsible. Although the flexural strength increases by $60 \%$ (713 vs. $445 \mathrm{MPa}$ ) for the $4: 1$ cermet over the $1.15: 1$ cermet, the increase going from $2: 1$ to $3: 1$ is a slight $12 \%$ ( 630 vs. $558 \mathrm{MPa}$ ). Similarly, fracture toughness increases by $70 \%$ for the $4: 1$ cermet over the 1.15 cermet (4.1 vs. $2.4 \mathrm{MPa} \cdot \mathrm{m}^{1 / 2}$ ), but only by $10 \%$ for the $3: 1$ cermet over the $2: 1$ cermet $\left(3.5\right.$ vs. $3.2 \mathrm{MPa} \cdot \mathrm{m}^{1 / 2}$ ). These modest bulk property increases cannot satisfactorily explain an abrupt change in the character of the ballistic response, particularly given that homogeneous materials with similar fracture toughnesses (alumina, boron carbide, etc.) behave in a purely brittle fashion under ballistic impact. This reinforces the conclusion that damage mitigation is achieved through crack deflection/arresting at the microstructural level during highly dynamic loading.

\section{Depth of Penetration Tests}

A preliminary assessment of residual depth of penetration of FSPs launched into thin chromium/chromium-sulfide samples with varying $\mathrm{Cr}: \mathrm{S}$ molar ratios was also performed as part of this study. While the $\mathrm{Cr} / \mathrm{CrS}$ cermet is unlikely to be useful in actual application, it is of fundamental interest to examine if the quasi-ductile response of the cermets with large volume fractions of metallic chromium can improve ballistic resistance compared to nearly homogeneous, brittle, CrS. Of particular interest is if the increased resistance to tensile failure from the crack arresting and deflecting properties of the metallic $\mathrm{Cr}$ particles would reduce material comminution ahead of the projectile. This could be ascertained indirectly via a marked reduction in residual depth of penetration, as precursor comminution is considered to be the primary mechanism controlling ballistic resistance for a given brittle material.

The samples were disks of $\mathrm{Cr} / \mathrm{CrS}$ cermet $6.4 \mathrm{~cm}$ in diameter, synthesized and prepared using the technique discussed in the "Material Synthesis and Sample Preparation" section. In order to maintain a constant sample areal density, the samples were cut with a thicknesses of 8.1, 6.9, 6.4, and $5.8 \mathrm{~mm}$, for the Cr:S molar ratios of 1.15:1, 2:1, $3: 1$, and $4: 1$ respectively, reflecting the increasing density of the samples with increasing $\mathrm{Cr}$ content (see Table 1). The samples were mounted directly in front of a solid rod of high density polyethylene (HDPE) with a length of $15 \mathrm{~cm}$ and a diameter of $7.6 \mathrm{~cm}$, which served as the backing material. The sample was left laterally unconfined. Consequently, high impedance confinement was absent in this experimental configuration. The metal backing was eliminated to maximize the magnitude of the residual penetration depth into the HDPE cylinder. The combined sample and HDPE cylinder were sandwiched between two flanges connected via a threaded rod, as shown in Fig. 7. The projectile was a chisel-nosed, mild-steel, 7.5-mm-diameter, 44-grain $(2.85 \mathrm{~g})$ FSP that was launched from a powder gun at a consistent velocity of $1715 \pm 10 \mathrm{~m} / \mathrm{s}$ as measured by a range Doppler radar system. After a test, the HDPE rod was cut in half along the axis of penetration and the residual DOP was measured as the final location of the FSP, as shown in Fig. 8.

The results of the tests, with three tests performed for each molar ratio $\mathrm{Cr}: \mathrm{S}$, are shown in Fig. 9. The average value of the DOP is indicated by the square symbol and the error bars represent the $90 \%$ confidence interval, assuming

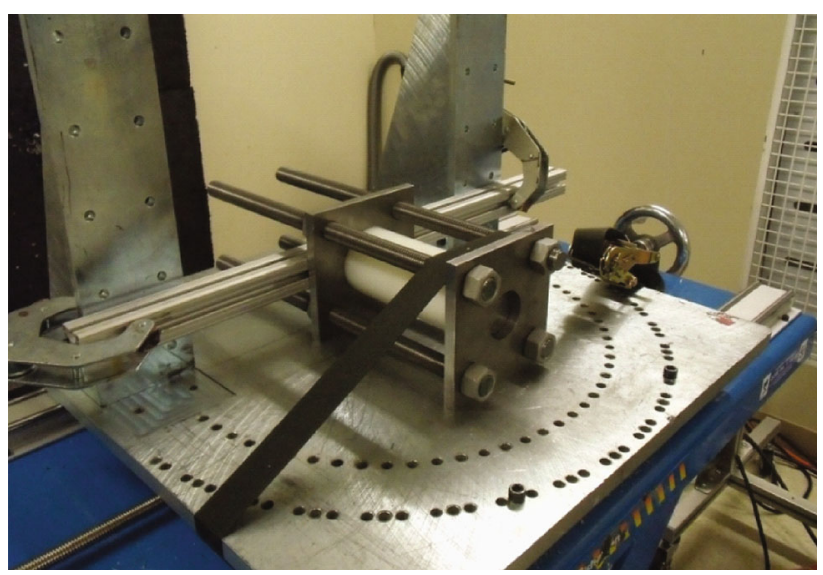

Fig. 7 Photograph of target and sample fixtures used to perform the residual DOP tests 

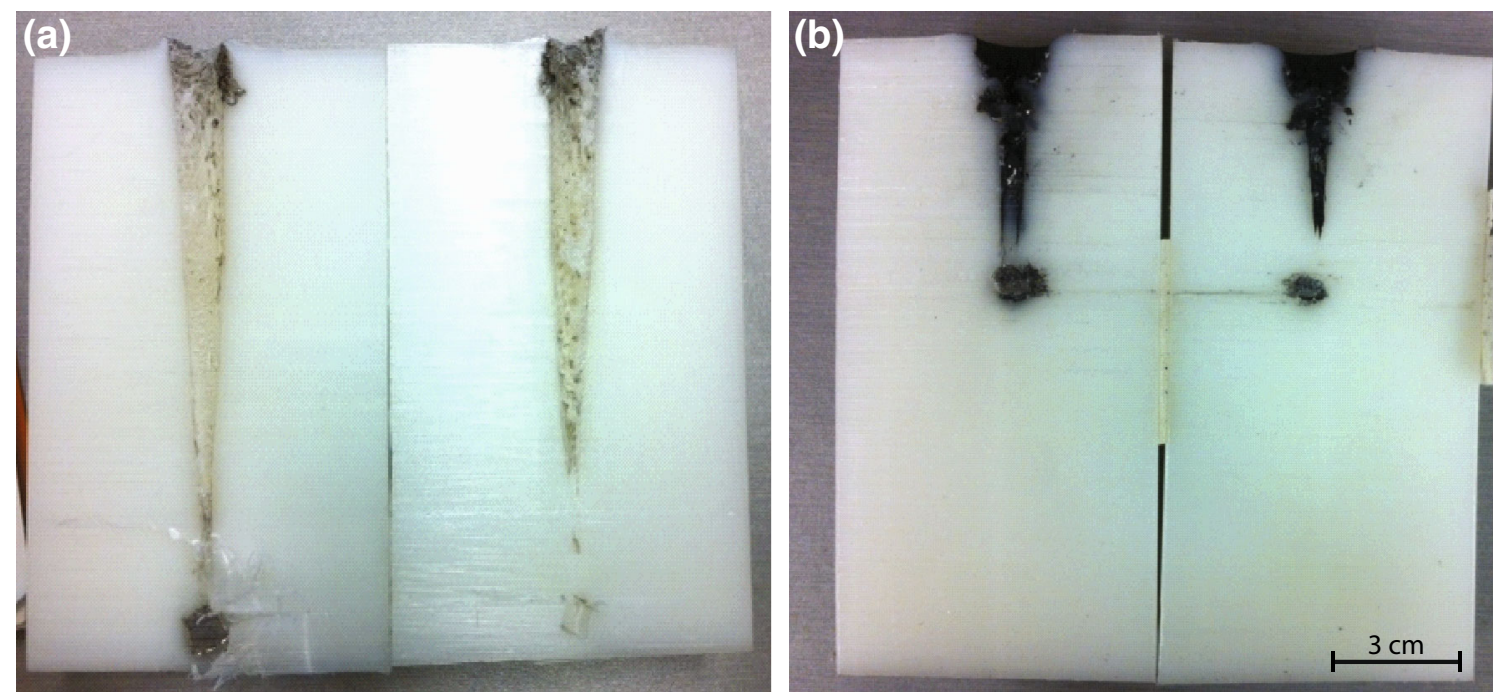

Fig. 8 Photograph of sectioned HDPE cylinders showing a the depth of penetration for an uncovered face, and $\mathbf{b}$ the depth of penetration when faced by a $1.15: 1$ cermet sample

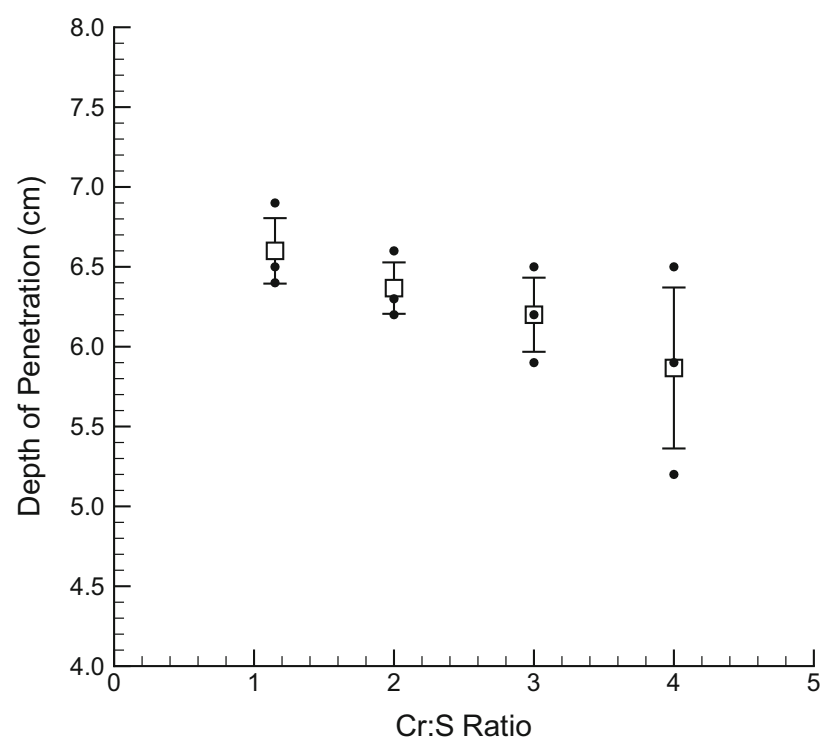

Fig. 9 Plot of residual depth of penetration into HDPE versus cermet molar fraction for an FSP impacting at $1715 \pm 10 \mathrm{~m} / \mathrm{s}$. Sample thickness was varied to maintain constant areal density

a normal distribution in the data scatter. Although the variation lies within the range of the error bars, a slight downward trend in DOP can be observed as the $\mathrm{Cr}$ content in the sample increases. We propose two explanations for this weak dependence. First, ballistic resistance of the material may be simply limited by the tensile strength of the weakest phase, which is the CrS in this case. This would explain why a $60 \%$ increase in bulk material flexural strength between the 1.15:1 and 4:1 compositions does not result in a significant reduction in the DOP. Second, the absence of a high impedance backing plate substantially reduces the pressure of reflected compression waves from the back of the sample. The lack of recompression may have permitted comminution of the $\mathrm{CrS}$ phase beneath the penetrator regardless of the metal content as the particles were incapable of sufficiently arresting or deflecting cracking, thereby eliminating any quasi-ductile behavior.

These results broadly confirm what has been observed in other literature: specifically that while cermets display increased damage resistance over homogeneous brittle materials, they do not demonstrate substantial protective advantages over the equivalent monolithic ceramic component when used as the protective element [22, 23]. A more promising implementation thus remains the employment of a cermet to functionally grade the interface between a conventional, homogeneous ceramic and a metal backing plate. In this configuration, the cermet enhances the defeat mechanism of the conventional confined ceramic system via damage mitigation, superior interface coupling and impedance matching $[21,24]$. This is particularly relevant for metal-ceramic systems with intermediate cermets that can be effectively manufactured, for example: titanium-diboride/titanium [21], alumina/aluminum-magnesium alloy [22, 23], and boron-carbide/aluminum [25-27].

\section{Conclusion}

The varying ballistic response of chromium/chromiumsulfide cermets, depending on the molar fraction of the reactants, illustrates the capability of tuning material behavior using the SHS manufacturing process. A transition from a purely brittle impact response typical of ceramics to a quasi-ductile response was observed when the stoichiometric ratio of chromium to sulfur was 
increased to 3:1 and beyond. Ductility was observed only in regions of high compressive loading beneath and around the penetrating impactor. Micrographs of the impact crater left in a highly metalized sample show that the ductility is supported by significant deformation of the chromium grains. The mechanism by which the interstitial chromium sulfide remains intact upon recovery is unclear, however, it is hypothesized that the chromium metal grains provide sufficient confinement such that the chromium sulfide is comminuted and dynamically re-compacted under very high compressive loadings. A unique, "reverse-cone" penetration cavity was observed in samples with high metal content. This contrasts with the typical fracture conoid observed in traditional ceramics, as well as the extensive, wide area through-cracking observed in low metal content $\mathrm{Cr} / \mathrm{CrS}$ cermets. It was further hypothesized that this is due to tensile failure beside the projectile, simultaneously with the confinement effects of the deforming chromium grains below the penetrator. Despite these substantial morphological differences in ballistic response with increasing metal content, preliminary residual depth of penetration tests showed only a weak dependence of ballistic resistance on molar ratio.

Acknowledgments This project was supported by an NSERC strategic Grant: "Design and Net-shape Manufacturing of Hybrid Composites for Ballistic Protection" (STPGP 380998-09). The authors would like to thank Anthony Devito for assistance in conducting the ballistic tests at McGill University, Arman Carter for assisting in sample synthesis and preparation, and Clint Hedge and Jean-Phillipe Dionne for conducting the DOP tests at Med-Eng (Ottawa, ON).

\section{References}

1. Karandikar PG, Evans G, Wong S, Aghajanian MK, Sennett M (2009) A review of ceramics for armor applications. Wiley, New York, pp 163-175. doi:10.1002/9780470456286.ch16

2. Shockey DA, Marchand A, Skaggs S, Cort G, Burkett M, Parker R (1990) Failure phenomenology of confined ceramic targets and impacting rods. Int J Impact Eng 9(3):263. doi:10.1016/0734743X(90)90002-D

3. Sternberg J (1989) Material properties determining the resistance of ceramics to high velocity penetration. J Appl Phys 65(9):3417

4. Lundberg P, Renström R, Lundberg B (2000) Impact of metallic projectiles on ceramic targets: transition between interface defeat and penetration. Int J Impact Eng 24(3):259. doi:10.1016/S0734743X(99)00152-9

5. Wilkins ML (1978) Mechanics of penetration and perforation. Int J Eng Sci 16(11):793. doi:10.1016/0020-7225(78)90066-6

6. Woodward RL (1990) A simple one-dimensional approach to modelling ceramic composite armour defeat. Int J Impact Eng 9(4):455. doi:10.1016/0734-743X(90)90035-T

7. Woodward RL, Gooch WA, Odonnell RG, Perciballi WJ, Baxter BJ, Pattie SD (1994) A study of fragmentation in the ballistic impact of ceramics. Int J Impact Eng 15(5):605. doi:10.1016/ 0734-743x(94)90122-2
8. Wilkins ML, Cline CF, Honodel CA (1969) Fourth progress report of light armor program. Technical Report, Lawrence Radiation Laboratory

9. Wilkins ML (1980) Ballistic materials and penetration mechanics, methods and phenomena. Elsevier, New York, pp 225-252. doi:10.1016/B978-0-444-41928-6.50015-6

10. Espinosa H, Brar N, Yuan G, Xu Y, Arrieta V (2000) Enhanced ballistic performance of confined multi-layered ceramic targets against long rod penetrators through interface defeat. Int J Solids Struct 37(36):4893. doi:10.1016/S0020-7683(99)00196-1

11. Roeder BA, Sun CT (2001) Dynamic penetration of alumina/ aluminum laminates: experiments and modeling. Int J Impact Eng 25(2):169. doi:10.1016/S0734-743X(00)00031-2

12. Yadav S, Ravichandran G (2003) Penetration resistance of laminated ceramic/polymer structures. Int J Impact Eng 28(5):557. doi:10.1016/S0734-743X(02)00122-7

13. Yabei G, Nesterenko VF (2007) Design and ballistic testing of Ti 6Al 4V matrix composites. J Compos Mater 41(19):2313. doi:10. 1177/0021998307075444

14. Wadley H, O’Masta M, Dharmasena K, Compton B, Gamble E, Zok F (2013) Indentation size effect and wear characteristics of spark plasma sintered, hard $\mathrm{MWCNT} / \mathrm{Al}_{2} \mathrm{O}_{3}$ nanocomposites. Int J Impact Eng 62:99. doi:10.1016/j.ijimpeng.2013.05.008

15. Chan HM (1997) Layered ceramics: processing and mechanical behavior. Annu Rev Mater Sci 27:249. doi:10.1146/annurev. matsci.27.1.249

16. Wedekind M, Both J, Baier H (2010) Thermo mechanical behaviour of metal matrix composite structures. Int J Mater Form 3(1):857. doi:10.1007/s12289-010-0905-y

17. Ibrahim IA, Mohamed FA, Lavernia EJ (1991) Particulate reinforced metal matrix composites: a review. J Mater Sci 26(5):1137. doi:10.1007/bf00544448

18. Li Y, Ramesh KT (1998) Influence of particle volume fraction, shape, and aspect ratio on the behavior of particle-reinforced metal-matrix composites at high rates of strain. Acta Mater 46(16):5633. doi:10.1016/S1359-6454(98)00250-X

19. Vaziri R, Delfosse G, Pageau D, Poursartip A (1993) High-speed impact response of particulate metal matrix composite materials: an experimental and theoretical investigation. Int J Impact Eng 13(2):329. doi:10.1016/0734-743X(93)90100-L

20. Clarke DR (1992) Interpenetrating phase composites. J Am Ceram Soc 75(4):739. doi:10.1111/j.1151-2916.1992.tb04138.x

21. Gooch WA, Burkins MS, Palicka R (1998) Proceedings of 17th international symposium on Ballistics, Midrand, South Africa

22. Chang H, Binner J, Higginson R (2010) Ballistic evaluation and damage characterization of metal-ceramic interpenetrating composites for light armor applications. Wiley, New York, pp 97-104. doi:10.1002/9780470944004.ch10

23. Chang H, Binner J, Higginson R, Myers P, Webb P, King G (2011) Preparation and characterisation of ceramic-faced metalceramic interpenetrating composites for impact applications. J Mater Sci 46(15):5237. doi:10.1007/s10853-011-5461-4

24. Templeton DW, Gorsich TJ, Holmquist TJ (2007) Proceedings of 23rd international symposium on Ballistics, Tarragona, Spain

25. Halverson DC, Pyzik AJ, Aksay IA, Snowden WE (1989) Processing of boron carbide-aluminum composites. J Am Ceram Soc 72(5):775

26. Stachiw J, Pyzik AJ, Carroll D, Prunier A, Allen T (1992) Boron carbide aluminum cermets for external pressure housing application. Tech. rep., Naval Command, Control and Ocean Surveillance Center, RDT\&E Division, TR \#1574

27. Pyzik AJ, Williams PD, McCombs A (1990) New low temperature processing for boron carbide/aluminum based composite armor. Tech. rep., Dow Chemical Company, ARO 266166-1-ms-A 
28. Merzhanov A (1996) Combustion processes that synthesize materials. J Mater Process Technol 56(1-4):222. doi:10.1016/ 0924-0136(95)01837-9

29. Merzhanov AG, Borovinskaya IP (2008) Historical retrospective of SHS: an autoreview. Int J Self-Propag High-Temp Synth 17(4):242. doi:10.3103/S1061386208040079

30. Subrahmanyam J, Vijayakumar M (1992) Self-propagating hightemperature synthesis. J Mater Sci 27(23):6249. doi:10.1007/ BF00576271

31. Goroshin S, Mizera A, Frost DL, Lee JHS (1996) Int Symp Combust 26(2):1883. doi:10.1016/S0082-0784(96)80010-5

32. Goroshin S, Camargo L, Lee JHS (2005) Liquid flame: combustion of metal suspensions in liquid sulfur. Proc Combust Inst 30(2):2561. doi:10.1016/j.proci.2004.08.045

33. Goroshin S, Higgins AJ, Jiang L, MacKay K, Ashrit PV (2005) Gasless combustion-driven heating elements for materials experiments in space. Microgravity Sci Technol 16(1-4):322. doi:10.1007/BF02945999
34. Nabavi A, Capozzi A, Goroshin S, Frost DL, Barthelat F (2014) A novel method for net-shape manufacturing of metal-metal sulfide cermets. J Mater Sci 49(23):8095. doi:10.1007/s10853014-8517-4

35. Tomoshige R, Niitsu K, Sekiguchi T, Oikawa K, Ishida K (2009) Some tribological properties of SHS-produced chromium sulfide. Int J Self-Propag High-Temp Synth 18(4):287. doi:10.3103/ s1061386209040104

36. Nabavi A, Goroshin S, Frost DL, Barthelat F (2015) Mechanical properties of chromium-chromium sulfide cermets fabricated by self-propagating high-temperature synthesis. J Mater Sci 50(9):3434. doi:10.1007/s10853-015-8902-7

37. Petel OE, Appleby-Thomas GJ, Hameed A, Capozzi A, Goroshin S, Frost DL, Hazell PJ (2014) Lateral stress evolution in chromium sulfide. J Phys 500(18):182031

38. Normandia MJ (2004) Impact response and analysis of several silicon carbides. Int J Appl Ceram Technol 1(3):226. doi:10. 1111/j.1744-7402.2004.tb00174.x 